\title{
Full stomachs at empty tides: tidal cycle affects feeding activity and diet of the sandy beach gastropod Olivella minuta
}

\author{
Helio H. Checon ${ }^{1,2}$, Mariana O. Silva ${ }^{1,3}$, Guilherme N. Corte ${ }^{1,2}$, Leonardo Q. Yokoyama ${ }^{4}$, \\ M. Alexandra Teodósio ${ }^{3}$ and Alexander Turra ${ }^{1}$ \\ ${ }^{1}$ Instituto Oceanográfico, Universidade de São Paulo, Praça do Oceanográfico, 191, 05508-120 São Paulo, Brasil: \\ ${ }^{2}$ Departamento de Biologia Animal, Universidade Estadual de Campinas, Rua Monteiro Lobato, 255, 13083-862 Campinas, São Paulo, Brasil; \\ ${ }^{3}$ CCMAR, Universidade do Algarve, FCT, Universidade do Algarve, Campus de Gambelas, 8005-139 Faro, Portugal; and \\ ${ }^{4}$ Laboratório de Ecologia e Gestão Costeira, Instituto do Mar, Universidade Federal de São Paulo, Rua Carvalho de Mendonça, 144, 11070-100 Santos, São Paulo, Brasil \\ Correspondence: H.H. Checon; e-mail: hchecon@yahoo.com
}

(Received 30 September 2019; editorial decision 31 January 2020)

\begin{abstract}
Olivella minuta is an abundant neogastropod on sandy beaches from Texas (USA) to southern Brazil. This study aimed to characterize and compare the feeding activity and diet of a Brazilian population of O. minuta in different tidal zones (intertidal and subtidal), and different tidal levels (high and low tides), with three combinations of tidal zone and level being studied (intertidal during low tide, intertidal during high tide and subtidal). The results showed that diet composition was generally similar among tidal conditions, with O. minuta being a generalist, feeding on 45 different food items. Feeding activity, however, was higher in the intertidal during low tide, whereas the richness and diversity of food items were higher in the intertidal during high tide. The higher feeding activity of $O$. minuta during low tide may be linked to a lower risk of predation; at low tide organisms may be able to feed for a longer time, and this may be particularly true on beaches with fine sand, where water retention is higher than that on beaches with coarse sand. The higher diversity of food items consumed in the intertidal during high tide is likely related to the increased prevalence of planktonic food during high tide. Our results indicate that tidal zone and level may strongly influence the feeding activity of coastal soft-bottom species and that species may show higher feeding activity during low tide. Given the current loss of intertidal habitats due to anthropogenic activity and climate-change associated factors, our study has important implications, highlighting the importance of intertidal areas for the ecology and conservation of sandy beach species.
\end{abstract}

\section{INTRODUGTION}

Coastal soft-bottom ecosystems, such as sandy beaches and tidal flats, are among the most dynamic, and are constantly shaped by anthropogenic pressures as well as natural drivers, such as tides, waves, currents and groundwater discharges (Defeo \& McLachlan, 2005; Schlacher et al., 2008; Piló et al., 2018). Tides cause constant changes in temperature, humidity, light and nutrient availability (Pinckeny \& Zingmark, 1991; Anthony, Ridd \& Orpin, 2004), which in turn affect the morphology and ecology of these environments as well as the activity and behaviour of organisms.

The constant and rhythmic movement of tides over coastal soft bottoms influences local biological assemblages. It facilitates the migration of individuals from the subtidal to the intertidal level, thereby altering species distribution (i.e. zonation) between periods of low and high tides (McLachlan, De Ruyck \& Hacking, 1996; Carcedo, Fiori \& Bremec, 2017). Furthermore, tidal movement alters both the availability of food and protection from desiccation (Phillips, 1977; Palmer, 1984; Skov et al., 2005; Chew et al., 2015; De Grande et al., 2018). Thus, the tide has a significant influence on aspects of the population biology of benthic species, such as distribution, growth, reproduction, behaviour and survival.

Tide is also known to influence the feeding behaviour of coastal benthic species. Its effects are readily apparent for suspension/filterfeeding species, which acquire organisms and particulate matter from the water column. Nevertheless, tide also directly affects the behaviour of deposit-feeding and predator species. For instance, on rocky shores, tidal variation affects the feeding rate of the predator sea star Pisaster ochraceus and the grazer snail Echinolittorina malaccana by changing their body temperature and level of activity during emersion or immersion periods (Pincebourde, Sanford \& Helmuth, 2008; Marshall \& McQuaid, 2011). In fact, various studies have shown that thermal stress and changes in food availability under low tides substantially alter the behaviour and feeding activity of intertidal species (Newell, Pye \& Ahsanullah, 1971; Esselink \& Zwarts, 1989; Wilson, 1989; Caron et al., 2004; Denny et al., 2011). 


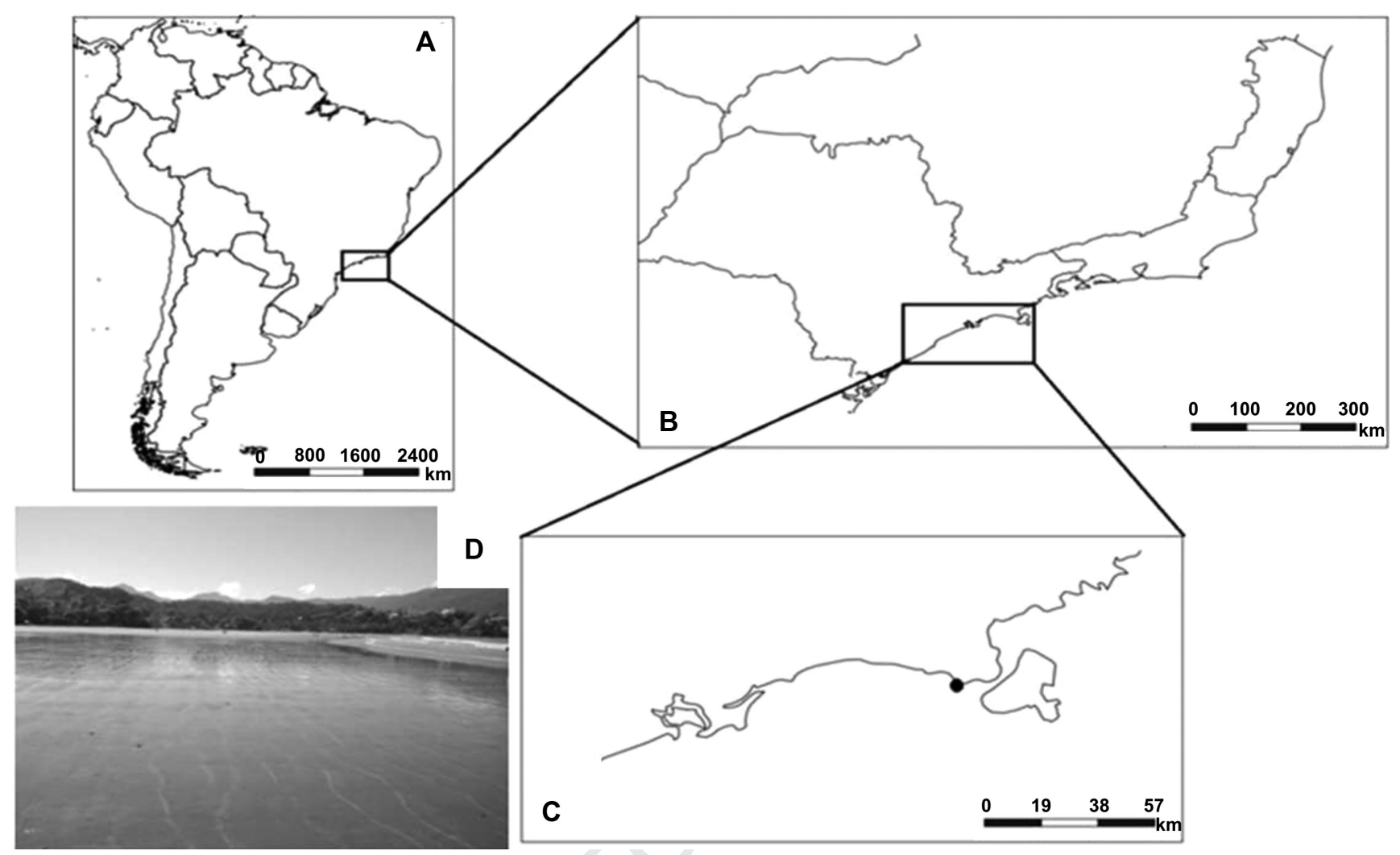

Figure 1. Map of Brazil $(\mathbf{A})$ showing the State of São Paulo $(\mathbf{B})$ and Barequeçaba Beach $(\mathbf{C}, \mathbf{D})$. The study site is indicated by the black dot in $(\mathbf{C})$.

While research on the influence of tide on the feeding behaviour of coastal benthic species has been carried out mainly in rocky shore habitats, the effect of tidal variation on soft-sediment species is still uncertain. Although both environments are influenced on a daily basis by tidal inundation, the relative importance of physical and biotic factors affecting species living in these two habitats differs significantly (Lake, 1990; Thiel \& Ulrich, 2002). While organisms inhabiting rocky shores are constantly exposed to heat stress, many soft-sediment species may avoid it by burying into the sediment (Phillips, 1977; Garrity, 1984). Thus, patterns and processes observed on rocky shores may not necessarily occur in soft sediments (Lake, 1990).

Gastropods are a diverse and abundant group on sandy beaches and play an important role in the functioning of coastal ecosystems due to their diverse range of feeding habits and significant contribution to energy flow (Arruda, Domaneschi \& Amaral, 2003; Kelaher, Levinton \& Hoch, 2003; Bergamino, Lercari \& Defeo, 2011; Petracco et al., 2014). According to Rhoads \& Young (1970), irrespective of the feeding habit of marine gastropods, their distribution and population composition (in terms of recruits and adults) are directly influenced by the pattern of food availability, which in turn depends on the hydrodynamic and morphodynamic states of the beach. While many species of sandy beaches occur in both the intertidal and subtidal zones, most studies focus only on the intertidal zone (Nel et al., 2014), and current understanding of the population dynamics of such species is compromised by the scarcity of data from the subtidal zone. Olivella minuta (Link, 1807) is found in sandy beach, tidal flat and estuarine habitats from Texas (USA) to southern Brazil and reaches densities of more than 3,000 individuals per strip transect (ind. $\mathrm{m}^{-1}$ ) in soft-bottom habitats (Petracco et al., 2014). Despite being an abundant consumer in coastal environments, studies of the feeding behaviour of 0 . minuta in sandy beaches are very scarce, and this is an obstacle to a correct under- standing of its ecological role. This species is known to feed on the sediment surface, where it searches for food with the propodium (Arruda et al., 2003). When a food item is found, the snail wraps the item on the metapodium and fully or partially ingests it by burying itself in the sediment and protracting the proboscis (Arruda et al., 2003). Thus far, a few studies have evaluated the diet of this species, classifying it as a carnivore/scavenger or omnivore based on the presence of a range of food items, such as crustaceans, foraminiferans, scaphopods and microalgae, in the stomach (Marcus \& Marcus, 1959: as Olivella verreauxi Ducros de Saint Germain, 1857; Arruda et al., 2003; Corte et al., 2019). These studies have provided important information on the feeding behaviour of $O$. minuta. However, they have examined only a small number of individuals or have not taken into account the effect of tidal zonation (intertidal vs subtidal) and level (high vs low tide) on feeding activity and diet composition. Olivella minuta is an abundant gastropod that can be found in both the intertidal and shallow subtidal areas of sandy beaches (Petracco et al., 2014; Checon et al., 2018). Therefore, it is a suitable model to investigate the influence of tide on the feeding behaviour of benthic species in soft sediments.

By comparing the feeding activity, strategy and the composition of the diet of $O$. minuta in different tidal zones (intertidal and subtidal) and at different tide levels (high and low tides), our aim was to investigate the influence of tide on the feeding behaviour and diet of $O$. minuta. We would expect food availability to be higher and thermal stress to be lower when the environment is submerged, so our expectation is that the diet composition and feeding activity of $O$. minuta would differ between intertidal and subtidal zones and between low and high tides. Specifically, based on the literature on rocky shores, our prediction was that $O$. minuta would show higher feeding activity in the subtidal and during periods of immersion in the intertidal. 


\section{MATERIAL AND METHODS}

Study area

This study was carried out at Barequeçaba Beach $\left(23^{\circ} 49^{\prime} 43^{\prime \prime} \mathrm{S}\right.$, $45^{\circ} 26^{\prime} 02^{\prime \prime} \mathrm{W}$ ) in the municipality of São Sebastião, northern coast of the State of São Paulo, Brazil (Fig. 1). Barequeçaba is a dissipative and low-energy-beach mesotidal system with a maximum tidal range of $2 \mathrm{~m}$. It is composed of a wide surf zone, gentle slope $\left(0.79^{\circ}\right)$ and fine/very fine sands $(3.19 \pm 0.19 \phi)$, with low organic matter content $(0.75 \pm 0.14 \%)$ (Nucci, Turra \& Morgado, 2001; Denadai, Amaral \& Turra, 2005).

\section{Sampling procedures}

Individuals of Olivella minuta were collected in March 2013 in the medium intertidal during high tide (IT-HT) and low tide (IT-LT), and also in the subtidal (ST) during spring low tides. Sampling in these areas was done on the same day to minimize daily variations in temperature and food availability, which could affect feeding and metabolic rates, and thus bias study results. Additionally, individuals from the intertidal area were collected at the end of the low and high tides; this was done to ensure that the feeding activity and diet were related to the appropriate tide level, and did not reflect the previous tide (e.g. activity of the low tide influenced by the high tide). In each area, 30 individuals with a shell length of $c .7 \mathrm{~mm}$ were collected from the sediment by passing sediment collected by a shovel through a $1 \mathrm{~mm}$ mesh in situ. Sampling was standardized in this way to minimize ontogeny-related differences in feeding rate and diet. To avoid halt digestion of stomach content, all individuals were fixed in $70 \%$ ethanol immediately on collection.

In the laboratory, the shell length (using a calliper) and weight were measured for the collected individuals; the body of each snail was then extracted by gently breaking the shell using a bench vise and the stomach was dissected. The stomach content was carefully examined under a stereomicroscope for all visible food items, as well as inorganic sediment fractions. Stomach contents were photographed and food items were counted and identified to the lowest possible taxonomic level with the help of taxonomic experts. The amount of inorganic material (sediment) in each stomach was estimated as dry weight $(\mathrm{g})$; the sediment was separated from the rest of the stomach contents, dried for $6 \mathrm{~h}$ at $80^{\circ} \mathrm{C}$ and then weighed.

\section{Data analysis}

Feeding activity: The hypothesis that tidal zone (intertidal and subtidal) and level (low and high tides) influence the feeding activity of $O$. minuta was investigated using three proxies for feeding activity: the stomach content weight (SCW), ingested sediment weight (ISW) and the stomach repletion index (SRI). SRI, which indicates the feeding activity of the specimens (Hyslop, 1980), was calculated using the following equation:

$$
\mathrm{SRI}=100(\mathrm{SW} / \mathrm{TW})
$$

where SW is the total weight of the stomach contents (to the nearest $0.0001 \mathrm{~g}$ ) and TW is the total individual organism weight (to the nearest $0.0001 \mathrm{~g}$ ). The individual organism weight did not vary between tidal conditions; for a normal distribution general linear model (GLM), $F_{2,57}=3.211$ and $P>0.05$. Therefore, weight was not a confounding factor in our analysis. The richness $(S$, the absolute number of different food items) and diversity $\left(H^{\prime}\right.$, the Shannon index) of food items were also calculated for each individual. Differences in these indices between tidal levels $($ IT-HT $\times$ IT-LT $\times$ ST) were evaluated using a GLM approach. Normal distribution models were used to investigate differences in SCW, ISW, diversity and evenness. A Poisson distribution GLM, which is suitable for count data (O'Hara \& Kotze, 2010), was used to analyse differences in the total number $(\mathcal{N})$ and richness $(S)$ of food items. A quasi-binomial
GLM, which is suitable for percentage data (Zuur et al., 2009), was used to evaluate differences in SRI. These analyses were tested for significance usually using $F$-tests, or in the case of the Poisson GLMs with chi-squared tests (Borcard, Gillet \& Legendre, 2011).

Diet composition: To evaluate the identity of the most important food items for $O$. minuta associated with the different tidal zone and levels, we calculated the numeric importance $(\mathrm{NI})$ and the frequency of occurrence (FO) for each food item. NI, which measures the relative contribution of a particular food item, is given by the following equation:

$$
\mathrm{NI}=\left(\frac{\mathcal{N}_{t i}}{\mathcal{N}}\right) \times 100
$$

where $\mathcal{N}_{t i}$ is the total number of the feeding item $i$ and $\mathcal{N}$ is the total number of all the feeding items. FO is given by the following equation:

$$
\mathrm{FO}=\left(\frac{\mathcal{N}_{e i}}{\mathcal{N}_{\ell}}\right) \times 100
$$

where $\mathcal{N}_{e i}$ is the number of individuals of $O$. minuta in which the food item was detected and $\mathcal{N}_{e}$ is the number of $O$. minuta specimens analysed.

The modified Costello graphical method (Amundsen, Gabler \& Staldvik, 1996) was used to illustrate and compare how feeding strategies of $O$. minuta varied with respect to tidal zones and levels. This is based on the relationship between the frequency of occurrence and the prey-specific abundance, and is calculated as

$$
P_{i}=\left(\frac{\sum S i}{\sum S t i}\right) \times 100
$$

where $S_{i}$ is the number of items $i$ in the stomach contents and $S_{t i}$ is the total number of items in all stomachs with contents containing item $i$. This calculation can indicate whether a species has a generalist or specialist feeding strategy (Amundsen et al., 1996).

To test the hypothesis that diet composition varied in relation to tide zone and level, we performed a PERMANOVA analysis (Anderson, 2001) on a Bray-Curtis dissimilarity matrix of food item abundance; a dummy variable with minimum abundance was added to account for zero-sum rows in the matrix (Clarke, Somerfield \& Chapman, 2006). If the PERMANOVA analysis was significant, we ran a permutational analysis of multivariate dispersion (PERMDISP) (Anderson, Ellingsen \& McArdle, 2006) to check whether there was any within-group variance heterogeneity that could mask the differences between tide zones and levels. In order to explore the possible differences within and between tidal zones and levels, a non-metric multidimensional scaling (NMDS) analysis was also carried out on the Bray-Curtis dissimilarity matrix mentioned earlier.

All analyses were done in $\mathrm{R}$ v. 3.5.0 ( $\mathrm{R}$ Development Team, 2018); we used the R packages vegan (Oksanen et al., 2018) and multcomp (Hothorn, Bretz \& Westfall, 2008), respectively, for multivariate analysis and post-hoc analysis of GLMs.

\section{RESULTS}

\section{Feeding activity}

A total of 1,739 food items belonging to 45 categories were detected in the stomachs of Olivella minuta (Supplementary Material Table S1). Macroalgae dominated (48\% of all food items identified) and were followed by microalgae $(15 \%)$, arthropods and foraminiferans (both $12 \%$ ), undefined items $(7 \%)$, poriferans $(3 \%)$, worms $(2 \%)$, molluscs and ciliates (both 1\%). Sediment was detected in the digestive tract of all individuals of $O$. minuta but was not considered as a food item. 


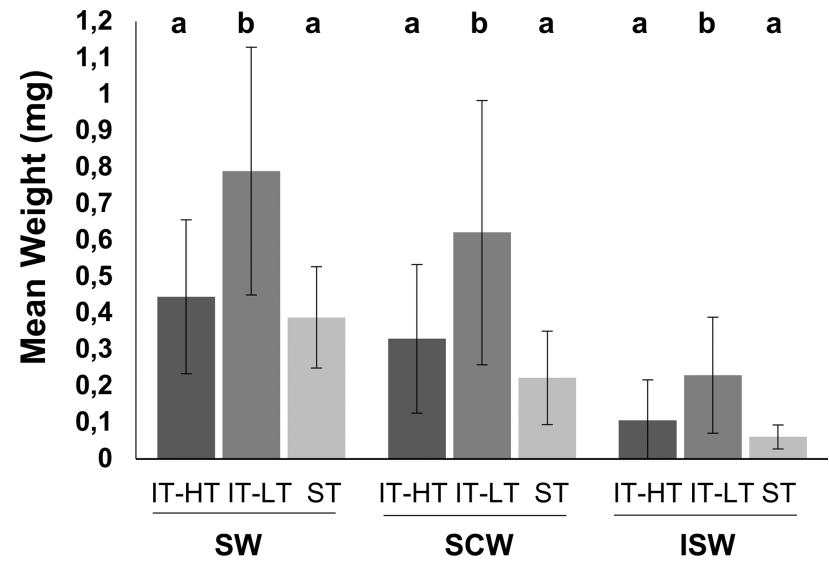

Figure 2. Mean weights $( \pm \mathrm{SD})$ of full stomach $(\mathrm{SW})$, stomach contents (SCW) and ingested sediment (ISW) of Olivella minuta for three tidal conditions. Two tidal conditions that are not significantly different from each other are indicated by the combination ' $a$, a', whereas two that are significantly different are indicated by the combination ' $a$, b'. Tidal conditions are shaded as follows: intertidal at high tide (IT-HT), dark grey; intertidal at low tide (IT-LT), mid grey; and subtidal (ST), light grey.

Contrary to our expectations, most of the food activity proxies evaluated indicated a higher feeding activity in the intertidal during low tide. The weight of ingested food items and of ingested sediment was higher when individuals were emersed (low tide) than when they were immersed (at high tide and in subtidal) (Fig. 2; Table 1). No difference was found between intertidal/high tide and subtidal conditions (Fig. 2). SRI showed a similar pattern, with higher values in the intertidal and at low tide (Fig. 3; Table 1). No difference was found in the overall abundance of food items consumed between tidal zones and levels. However, the total richness and diversity of consumed items were higher in the intertidal during high tide (Table 1; Fig. 3).

\section{Diet composition}

Among the 45 food items found in the stomachs of $O$. minuta (Supplementary Material Table S1), 10 were classified as the most important based on their numeric importance and frequency of occurrence (Table 2). The most important and frequent food items ranged from macroalgae (Debresia sp., Colpomenia sp., Ulva sp. and green algae sp. 1) and microalgae (centric diatoms) to foraminiferans (Miliolidae and Foraminifera sp. 1) and crustaceans. Unidentified animal and plant remains were also common in the stomachs of $O$. minuta. The range of food items recorded for $O$. minuta points to this mollusc being a generalist species.

This is shown in the relationship between the prey-specific abundance and the frequency of occurrence of food items (Fig. 4). Al-

Table 1. Linear model tests used to investigate differences found for individual variables among tidal zones and levels.

\begin{tabular}{lllccr}
\hline Variable & Distribution & df & Res. df & Test value & $P$-value \\
\hline SW & Normal & 2 & 87 & 23.653 & $<\mathbf{0 . 0 0 1}$ \\
SCW & Normal & 2 & 87 & 20.011 & $<\mathbf{0 . 0 0 1}$ \\
ISW & Normal & 2 & 87 & 18.484 & $<\mathbf{0 . 0 0 1}$ \\
SRI & Quasi-binomial & 2 & 27 & 7.694 & $\mathbf{0 . 0 0 2}$ \\
Richness & Poisson & 2 & 87 & 6.899 & $\mathbf{0 . 0 3 1}$ \\
Abundance & Quasi-Poisson & 2 & 87 & 2.257 & 0.871 \\
Diversity & Normal & 2 & 87 & 6.252 & $\mathbf{0 . 0 0 3}$ \\
\hline
\end{tabular}

Significant $P$-values are indicated in bold font. Abbreviations: SW, stomach weight; SCW, stomach content weight; ISW, ingested sediment weight; SRI, stomach repletion index; df, degrees of freedom; res. $\mathrm{df}$, residual degrees of freedom. though there is a slight tendency towards specialization in subtidal individuals, the plot shows that overall $O$. minuta consumes many items at low frequency and low specificity (in terms of abundance); the low dominance of the prey taxa consumed and low specialization in the diet are characteristic of a generalist feeding strategy.

Our results show that the relative importance of food items differs among sampling conditions. For instance, macroalgae Derbesia sp. was relatively more important at the intertidal during low tide and high tide, whereas Colpomenia sp. was important only during low tide. In contrast, Ulva sp. was an important food item only during immersion (in the intertidal during high tide and in the subtidal). Miliolid foraminiferans were important in the intertidal during low tide, whereas Foraminifera sp. 1 was important mainly in the intertidal during high tide. Other food items, such as crustaceans and centric diatoms, were more important when conditions were such that snails were immersed.

The PERMANOVA $\left(F_{2,87}=3.322, R^{2}=0.071, P<0.001\right)$ showed that there were differences in the composition of diet for all the pairwise combinations of tidal zone and level evaluated: ITLT vs IT-HT: $F=4.517, R^{2}=0.072, P<0.001$; IT-LT vs ST: $F=3.619, R^{2}=0.058, P=0.003$; IT-HT vs ST: $F=2.882$, $R^{2}=0.047, P=0.009$. However, the PERMDISP showed that differences among groups may reflect variations in diet among individuals of the same group (i.e. high heterogeneity within each group) rather than overall differences in diet composition between tidal conditions $\left(F_{2,87}=10.564, P<0.001\right)$. This is clearly apparent in the ordination of diet composition (Fig. 5). This shows significant overlap of diet composition among groups, as well as strong variation within each group (particularly marked for the subtidal and intertidal/low tide groups). Thus, despite differences in the dominance of food items, overall diet composition did not differ among the tidal zones and levels evaluated.

\section{DISCUSSION}

Our results did not support our hypothesis. In fact, the feeding activity of Olivella minuta was higher during periods of low tide. The richness and diversity of food items in the intertidal were higher during high tide than low tide. Moreover, the overall composition of the diet was similar across individuals from the different tidal zones and levels studied.

Paralleling data from rocky shores (Newell et al., 1971; Denny et al., 2011; Marshall \& McQuaid, 2011), our study showed that tidal variation can also affect feeding on soft bottoms. On rocky shores, much of the variation in feeding can be explained by thermal stress and absence of water flow for filter feeders (Denny et al., 2011; Marshall \& McQuaid, 2011). On soft bottoms, thermal stress may be lowered by organisms burrowing into the sediment and the interstitial water in the sediment. Nevertheless, soft-bottom species may be subjected to thermal stress. For instance, O. minuta is thought to migrate towards lower areas of the intertidal zone during warmer seasons to avoid desiccation (Arruda et al., 2003; Petracco et al., 2014; Dahlet et al., 2019). The direction of the thermal stress effect (i.e. whether it is positive or negative) on the feeding of intertidal species is not easy to predict and, although thermal stress may be detrimental to feeding activity (Whitlatch \& Obrebski, 1980; Marshall \& McQuaid, 2011), it may enhance feeding during acute exposures of short duration (Pincebourde et al., 2008). This enhanced feeding may compensate for the energetic costs of thermal stress (Pincebourde et al., 2008). However, no studies have been carried out on the metabolism of $O$. minuta and, given the varied effects of thermal stress on gastropod species, we cannot generalize from other species. Further studies are required to clarify our understanding of the effect of thermal stress on the feeding activity of O. minuta.

Enhanced feeding activity during emersion may also reflect reduced predation pressures. With the incoming tide, the risk of pre- 

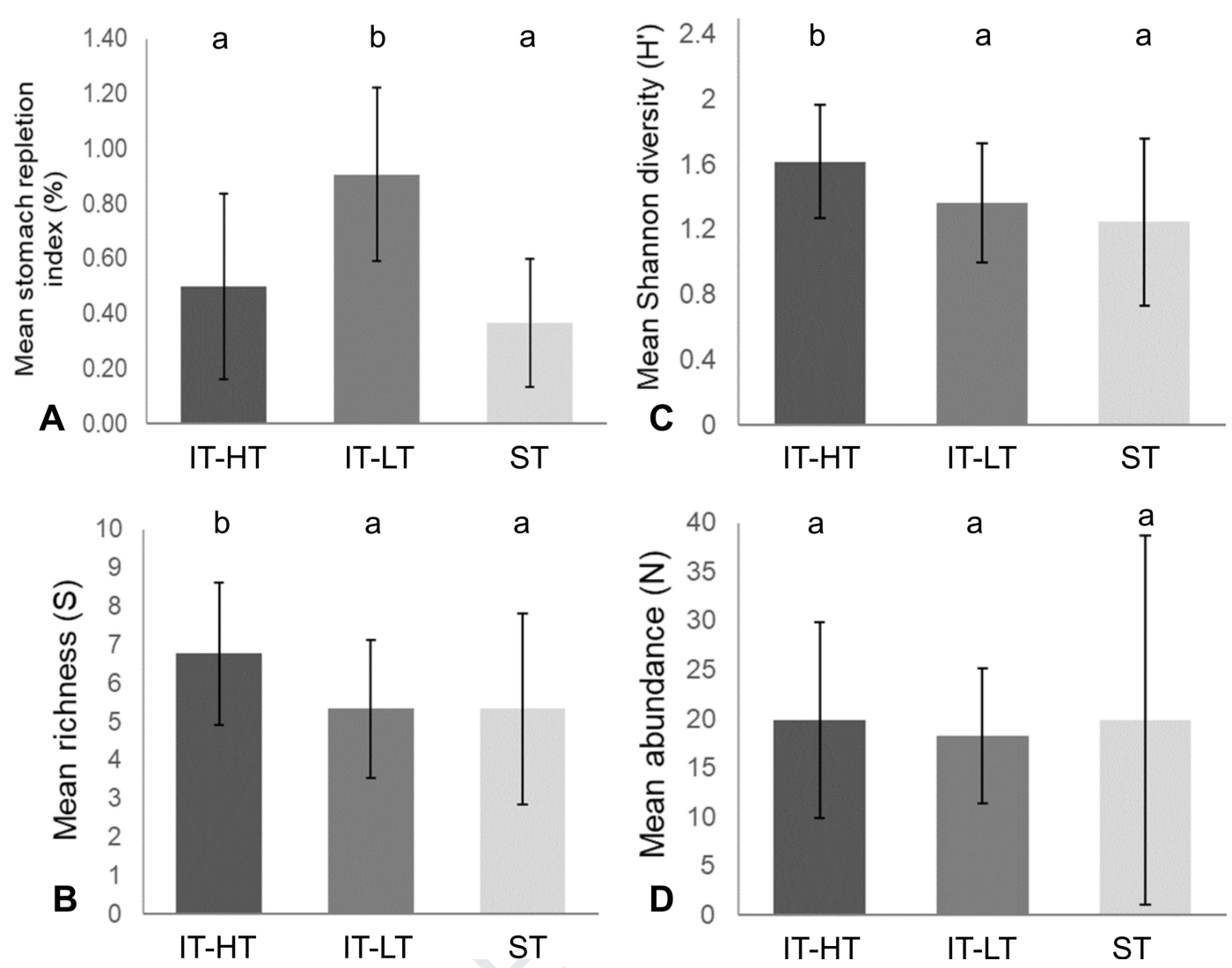

Figure 3. Mean $( \pm \mathrm{SD})$ of stomach repletion index $(\mathbf{A})$, richness $(\mathbf{B})$, diversity (Shannon $\left.H^{\prime}\right)(\mathbf{C})$ and abundance $(\mathbf{D})$ of food items found in the stomach of Olivella minuta in the three tidal conditions. Two tidal conditions that are not significantly different from each other are indicated by the combination 'a, a', whereas two that are significantly different are indicated by the combination 'a, b'. Tidal conditions are shaded as follows: intertidal at high tide (IT-HT), dark grey; intertidal at low tide (IT-LT), mid grey; subtidal (ST), light grey.

Table 2. Numeric importance (NI) and frequency of occurrence (FO) (\%) of the most important food items found in the stomachs of Olivella minuta in each tidal zone and at each tidal level.

\begin{tabular}{|c|c|c|c|c|c|c|}
\hline \multirow[b]{2}{*}{ Food items } & \multicolumn{2}{|c|}{ IT-HT } & \multicolumn{2}{|c|}{ IT-LT } & \multicolumn{2}{|c|}{ ST } \\
\hline & $\mathrm{NI}$ & FO & $\mathrm{NI}$ & FO & $\mathrm{NI}$ & FO \\
\hline Derbesia sp. (macroalgae) & 13.23 & 56.67 & 8.56 & 36.67 & 3.53 & 23.33 \\
\hline Non-plant fibres & 12.40 & 83.30 & 18.40 & 73.30 & 13.28 & 60.00 \\
\hline Crustaceans & 10.05 & 26.67 & 1.82 & 23.33 & 14.62 & 40.00 \\
\hline Green algae sp. 1 & 9.88 & 53.30 & 4.01 & 20.00 & 4.87 & 23.30 \\
\hline Foraminifera sp. 1 & 7.37 & 56.67 & 2.73 & 30.00 & 0.84 & 13.33 \\
\hline Colpomenia sp. (macroalgae) & 5.69 & 50.00 & 24.95 & 60.00 & 12.23 & 36.67 \\
\hline Ulva sp. (macroalgae) & 7.04 & 60.00 & 0.91 & 10.00 & 8.57 & 40.00 \\
\hline Miliolidae (Foraminifera) & 5.19 & 50.00 & 10.38 & 56.67 & 2.52 & 30.00 \\
\hline Plant fibres & 4.19 & 3.33 & 4.55 & 26.67 & 1.34 & 13.33 \\
\hline Centric diatoms & 5.86 & 36.67 & 0.18 & 3.33 & 6.72 & 33.33 \\
\hline
\end{tabular}

The five most important food items, as quantified by the two metrics for each tidal condition, are shown in bold font. Abbreviations: IT-HT, intertidal/high tide; IT-LT, intertidal/low tide; ST, subtidal.

dation may be increased due to the increased prevalence of potential nektonic and subtidal benthic predators in the intertidal area. In fact, experimental studies show that predation of benthic species may increase significantly during high tide (Esselink \& Zwarts, 1989; Wilson, 1989). Olivella minuta is preyed upon by many subtidal and/or nektonic species, such as teleost fishes, rays and starfishes (Denadai et al., 2015; Fernandez et al., 2017; Angelini et al.,
2018). Thus, it is logical to assume that when submerged (both in the subtidal and in the intertidal during high tides) this species is under significant pressure from predators. Evidence for this hypothesis is provided by another species of Olivella, O. biplicata, which is able to distinguish potential predators; when sensing the presence of a starfish, it immediately buries itself in the sediment to avoid predation (Phillips, 1977). This behaviour likely reduces the time available for feeding and this may be one explanation for reduced feeding activity when submerged in subtidal and high tide conditions. We would argue, however, that beach characteristics are likely to have an impact on the final outcome. The fine sands of beaches such as Barequeçaba enhance the retention of water during low tides (Namikas et al., 2010), whereas on coarse-grained beaches, the sediment is kept moist and so intertidal species are able to feed in an environment that is subject to less desiccation-related stress (Dye, 1980).

Although the feeding activity of $O$. minuta was higher in the intertidal during low tide, the richness and diversity of consumed food items were higher in the intertidal during high tide. This may be explained by the presumed greater availability of food items when the tide comes in (i.e. brought in by tide). The gut contents of $O$. minuta contained planktonic organisms, such as centric diatoms, the cyanobacteria Pseudoanabaena sp. and tintinnid ciliates, which reach the intertidal zone during high tide. There is also an increase in the prevalence of macroalgae, an important food item, with the incoming tide. Thus, the enhanced diversity and richness of food items consumed in the intertidal during high tide may be a result of food resources that are brought in during high tide.

The results on feeding activity and food diversity, when taken together, suggest that individuals in the subtidal may have less time 


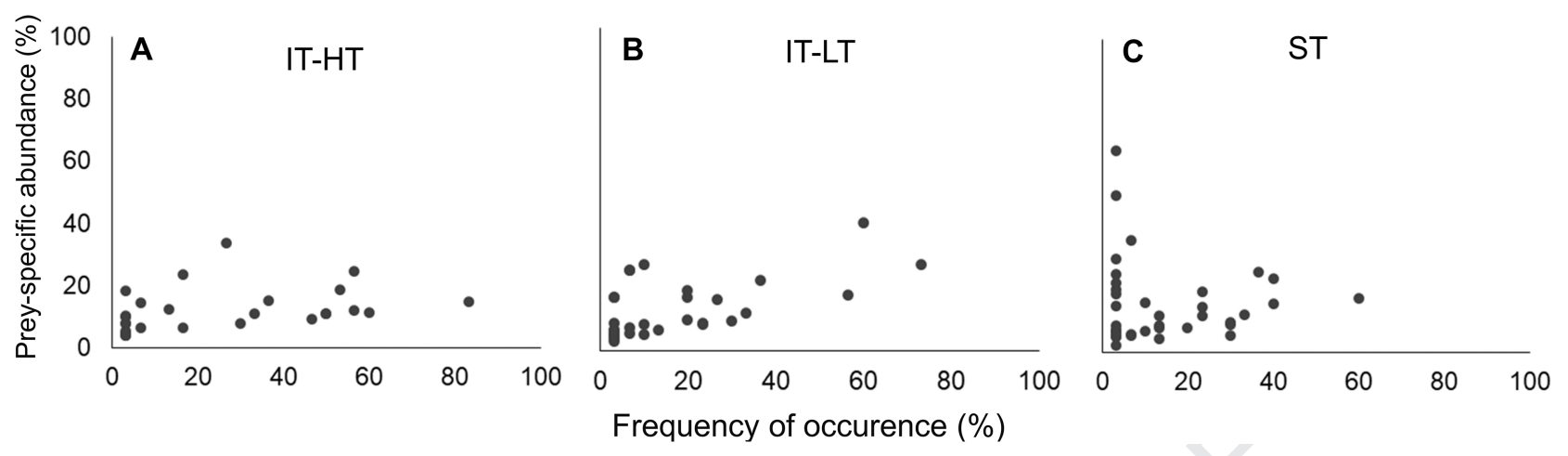

Figure 4. Modified Costello graphic representation of the relationship between prey-specific abundance (\%) and frequency of occurrence (\%) for food items found in Olivella minuta sampled in the three tidal conditions: the intertidal zone during high tide (IT-HT) (A), intertidal during low tide (IT-LT) (B) and the subtidal (ST) $(\mathbf{C})$. Each dot in a plot represents a particular food item ( $n=$ IT-HT, 32; IT-LT, 27; SL, 36).

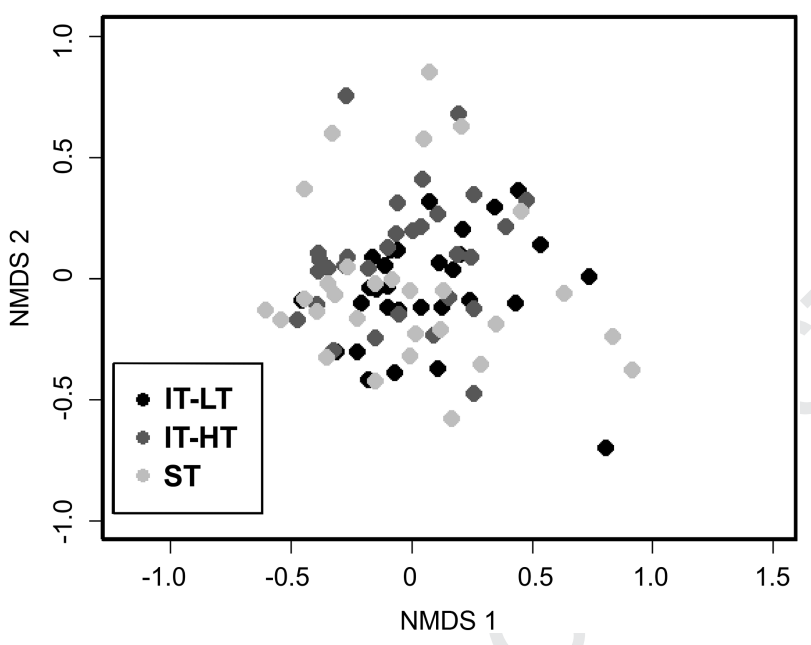

Figure 5. NMDS plot showing the variation in the food items consumed by individual Olivella minuta $(n=90)$ across the three tidal conditions studied. Each dot represents an individual snail. The plot was based on the BrayCurtis dissimilarity measure and had a stress value of 0.19 . Abbreviations and sample sizes for tidal conditions: IT-HT, intertidal at high tide $(n=30)$; IT-LT, intertidal at low tide $(n=30)$; and ST, subtidal $(n=30)$.

for feeding, predation pressure being greater and the diversity of available food items being lower. In this sense, the intertidal zone of Barequeçaba Beach seems to be an optimal habitat for $O$. minuta and this is at least partly supported by data available for $O$. biplicata. Olivella biplicata is known to exhibit ontogenetic changes in distribution, with adults migrating towards higher tidal levels (they are more tolerant of desiccation and are able to explore more resources in this area due to the lower predation pressure), whereas juveniles tend to be concentrated in the subtidal zone (Edwards, 1969). In $O$. minuta, recruits have been found mainly in the lower intertidal zone, close to the water line (Petracco et al., 2014). While we attempted to control for the effect of ontogeny, our findings suggest that individuals can feed for a longer time and are able to find a greater range of food items with the incoming tide, and that this is especially the case on beaches with fine sands, where water retention is higher than that on beaches with coarse sand (McLachlan \& Turner, 1994) and lower desiccation stress. The higher feeding activity of $O$. minuta in the intertidal zone might make this species more vulnerable to the loss of intertidal habitat arising from coastal armouring (Morley, Toft \& Hanson, 2012) and climate change (Schlacher et al., 2008).

With regard to the identity and composition of food items, our results show that $O$. minuta is a generalist predator, which consumes a variety of different food items, ranging from macroalgae and microalgae to foraminiferans and crustaceans. This generalist behaviour contrasts with previous studies on the diet of this species. Marcus \& Marcus (1959) and Arruda et al. (2003) classified $O$. minuta as a carnivore. Our results, however, indicate that this species should be regarded as an omnivore; our data show that the diet ranges from autotrophic (microalgae and macroalgae) to heterotrophic prey, and this agrees with the results of a recent study by Corte et al. (2019). We found macroalgae to be a dominant component of the diet and this contrasts with previous studies of the diet of O. minuta (Marcus \& Marcus, 1959; Arruda et al., 2003; Corte et al., 2019). Our findings may reflect increases in drifting and beach-cast macroalgae due to seasonal or stochastic events (e.g. storms) at Barequeçaba (H. Checon, personal observation). Although our results are likely to have been influenced by seasonal events, they nonetheless highlight the omnivorous diet and opportunistic feeding behaviour of 0 . minuta; this species is known to be able to shift its diet in response to temporal changes in the environment (Corte et al., 2019). Evidence from stable isotope analysis showing that $O$. minuta feeds on more than one trophic level (Angelini et al., 2018) also supports the view that this species is an omnivore. A recent study has shown opportunistic suspension feeding in Olivella columellaris with increasing food supply (Morse \& Peters, 2016). Such behaviour could explain the abundance of ingested macroalgae in $O$. minuta, especially during immersion; studies are needed to confirm whether this is the case. The recognition of this species as an omnivore is important given its abundance on soft-bottom habitats (Petracco et al., 2014) and the overall stability that the multiple links established by omnivore species confer on the ecosystem (Link, 2002; Dunne, Williams \& Martinez, 2004). An omnivorous diet may also be advantageous for the growth of generalist species, in comparison to the diet of strictly carnivorous or herbivorous species, such as the nassariid Tritia obsoleta (Curtis \& Hurd, 1979: as Ilyanassa obsoleta).

We also found that regardless of tide zone or level, a large quantity of sediment was ingested by all the individuals of $O$. minuta studied. The presence of sand in the digestive tract of gastropods is considered to be due to the non-selective nature of feeding, with the sediment and attached food items (microalgae and bacteria) being ingested and only the latter being digested (Curtis \& Hurd, 1979; López \& Cheng, 1983). The prevalence of sediment particles and diatoms in the gut contents examined by us suggests that $O$. minuta exhibits non-selective deposit-feeding behaviour. As has been hypothesized by Malaquias et al. (2004), sediment ingestion may also be a mechanism to facilitate digestion via crushing of food items.

We found that the importance of food item varied among the different tidal zones and levels. Microalgae, for instance, were most commonly found during periods of immersion. This result is interesting given that there is vertical migration of microalgae in the sediment in relation to tidal variation, with microalgae being located 
deeper within the sediment during immersion and on the surface during low tide (Serôdio et al., 2006). However, this migration does not seem to limit the feeding of O. minuta. This is also the case for the hydrobiid mollusc Peringia ulvae (Vieira et al., 2010: as Hydrobia ulvae); a possible explanation could be the subsuperficial feeding behaviour noted for this species (Arruda et al., 2003; Petracco et al., 2014). The presence of the rocky shore-associated green algae Ulva sp. and the seagrass-associated green algae Derbesia sp. in the gut contents of $O$. minuta during high tide may reflect the nutrient input from allochthonous sources at high tide into the intertidal zone of sandy beaches (Lastra et al., 2008; Quillien et al., 2015).

Despite these differences, overall we found no changes in food composition among the tidal zones and levels evaluated. This lack of variation is likely related to the generalist behaviour of O. minuta. It has been suggested that generalist benthic organisms ingest all the prey items that they encounter, with the stomach contents reflecting the general abundance of food items in the environment (Evans, 1983). The generalist diet of O. minuta, however, may also reflect high intraspecific variability in diet within and among habitats; this is possible when available food resources are diverse and patchily distributed, so that there is significant overlap between different habitats (Nordstrom et al., 2010).

Given that global warming is expected to lead to global increases in sea level and thus to changes in the tidal conditions in coastal areas, our results have implications for understanding and predicting future scenarios (Helmuth et al., 2006; Denny et al., 2011). The ongoing process of coastal squeeze (i.e. due to the increasing urbanization of coastal areas; Pontee, 2013) coupled with the predicted rise in global sea levels has been linked with the reduction of intertidal areas worldwide. Among other impacts, these processes are likely to limit the potential landward migration of intertidal species and will reduce emersion times (Martinez et al., 2014). Thus, barring adaptations by intertidal organisms in response to these changes, the feeding may be negatively impacted by the wide-scale loss of intertidal habitat. In such a scenario, species such as $O$. minuta may suffer a reduction in feeding activity and this in turn may affect the species at the population level.

\section{SUPPLEMENTARY MATERIAL}

Supplementary material is available at Fournal of Molluscan Studies online.

\section{ACKNOWLEDGEMENTS}

We would like to thank Rita M. Camargo for help with sampling procedures. We also thank the following taxonomic experts for assistance with the identification of gut contents: Estibaliz Berecibar (macroalgae), Ana Barbosa (microalgae), Sarita Camacho (foraminiferans), Ann Vanrusel (nematodes) and Ernest Schockaert (platyhelminths). This work was supported by research grants awarded to AT from the Conselho Nacional de Desenvolvimento Científico e Tecnológico (CNPQ) (Proc. 484475/2011-8 and 309697/2015-8) and the Fundação de Amparo à Pesquisa do Estado de São Paulo (FAPESP) (Proc. 2009/17585-6), and by post-doctoral grants awarded to HHC (Proc. 2018/22036-0), GNC (Proc. 2017/17071-9) and LQY (Proc. 2009/15893-5). This study was also partly supported by Portuguese Foundation for Science and Technology through the project UID/Multi/04326/201s

\section{REFERENCES}

AMUNDSEN, P.-A., GABLER, H.-M. \& STALDVIK, F.J. 1996. A new approach to graphical analysis of feeding strategy from stomach data contents - modification of the Costello (1990) method. Fournal of Fish Biology, 48: 607-614.
ANDERSON, M.J. 2001. A new method for non-parametric multivariate analysis of variance. Austral Ecology, 26: 32-46.

ANDERSON, M.J., ELLINGSEN, K.E. \& McARDLE, B.H. 2006. Multivariate dispersion as a measure of beta diversity. Ecology Letters, 9: 683693.

ANGELINI, R., CONTENTE, R.F., ROSSI-WONGTSCHOWSKI, C.L.B.D., SOARES, L.S.H., SCHAEFFER-NOVELLI, Y., LOPES, R.M., MANCINI, P.L., GOLL, M. \& AMARAL, A.C.Z. 2018. Ecosystem modelling as a framework to convert a multi-disciplinary research approach into a useful model for the Araçá Bay (Brazil). Ocean \& Coastal Management, 164: 92-103.

ANTHONY, K.R.N., RIDD, P.V. \& ORPIN, A.R. 2004. Temporal variation of light availability in coastal benthic habitats: effects of cloud, turbidity and tides. Limnology \& Oceanography, 49: 2201-2211.

ARRUDA, E.P., DOMANESCHI, O. \& AMARAL, A.C.Z. 2003. Mollusc feeding guilds on sandy beaches in São Paulo State, Brazil. Marine Biology, 143: 691-701.

BERGAMINO, L., LERCARI, D. \& DEFEO, O. 2011. Food web structure in sandy beaches: temporal and spatial variation using stable isotope analysis. Estuarine, Coastal and Shelf Science, 91: 536-543.

BORCARD, D., GILLET, F. \& LEGENDRE, P. 2011. Numerical ecology with $R$. Springer, New York.

CARCEDO, M.C., FIORI, S.M. \& BREMEC, C.S. 2017. Zonation of macrobenthos across a mesotidal sandy beach: variability based on physical factors. Fournal of Sea Research, 121: 1-10.

GARON, A., Desrosiers, G., Olive, P.J.W., Retière, G. \& NOZAIS, C. 2004. Comparison of diet and feeding activity of two polychaetes, Nephtys caeca (Fabricius) and Nereis virens (Sars), in an estuarine intertidal environment in Quebec, Canada. Fournal of Experimental Marine Biology and Ecology, 304: 225-242.

GHECON, H.H., VIEIRA, D.C., CORTE, G.N., SOUSA, E.G.P.M., FONSECA, G. \& AMARAL, A.C.Z. 2018. Defining soft-bottoms and potential indicator species as tools for monitoring coastal systems: a case study in a subtropical bay. Ocean \& Coastal Management, 164: 68-78.

CHEW, L.L., GHONG, V.C., OOI, A.L. \& SASEKUMAR, A. 2015. Vertical migration and positioning behavior of copepods in a mangrove estuary: interactions between tidal, diel light and lunar cycles. Estuarine, Coastal and Shelf Science, 152: 142-152.

CLARKE, K.R., SOMERFIELD, P.J. \& CHAPMAN, M.G. 2006. On resemblance measures for ecological studies, including taxonomic dissimilarities and a zero-adjusted Bray-Curtis coefficient for denuded assemblages. Fournal of Experimental Marine Biology and Ecology, 330: 55-80.

CORTE, G.N., YOKOYAMA, L.Q., GHECON, H.H. \& TURRA, A. 2019. Spatial and temporal variation in the diet of the gastropod Olivella minuta, a sandy beach key species. Invertebrate Biology, 138: e12269.

CURTIS, L.A. \& HURD, L.E. 1979. On the broad nutritional requirements of the mud snail, Ilyanassa (Nassarius) obsolete (Say), and its polytrophic role on food webs. Fournal of Experimental Marine Biology and Ecology, 41: 289-297.

DAHLET, L.I., CHECON, H.H., YOKOYAMA, L.Q. \& TURRA, A. 2019. Patterns of shell utilization by hermit crabs as a proxy of gastropod population dynamics. Marine Biology Research, 15: 424-433.

DEFEO, O. \& McLACHLAN, A. 2005. Patterns, processes and regulatory mechanisms in sandy beach macrofauna: a multi-scale analysis. Marine Ecology Progress Series, 295: 1-20.

DE GRANDE, F.R., COLPO, K.D., QUEIROGA, H., CANNICAI, S. \& COSTA, T.M. 2018. Contrasting activity patterns at high and low tides in two Brazilian fiddler crabs. Fournal of Crustacean Biology, 28: 407-412.

DENADAI, M.R., AMARAL, A.C.Z. \& TURRA, A. 2005. Structure of molluscan assemblages in sheltered intertidal unconsolidated sediments. Brazilian Archives of Biology and Technology, 48: 825-839.

DENADAI, M.R., SANTOS, F.B., BESSA, E., FERNANDEZ, W.S., LUVISARO, C. \& TURRA, A. 2015. Feeding habits of the whitemouth croker Micropogonias furneri (Perciformes; Sciaenidae) in Caraguatatuba Bay, southeastern Brazil. Brazilian Fournal of Oceanography, 63: 125134.

DENNY, M.W., DOWD, W.W., BILIR, L. \& MACH, K.J. 2011. Spreading the risk: small-scale body temperature variation among intertidal organisms and its implication for species persistence. Fournal of Experimental Marine Biology and Ecology, 400: 175-190. 
DUNNE, J.A., WILLIAMS, R.J. \& MARTINEZ, N.D. 2004. Network structure and robustness of marine food webs. Marine Ecology Progress Series, 273: 291-302.

DYE, A.H. 1980. Tidal fluctuations in biological oxygen demand in exposed sandy beaches. Estuarine and Coastal Marine Science, 11: 1-8.

EDWARDS, D.C. 1969. Zonation by size as an adaptation for intertidal life in Olivella biplicata. Integrative and Comparative Biology, 9: 399-417.

ESSELINK, P. \& ZWARTS, L. 1989. Seasonal trend in burrow depth and tidal variation in feeding activity of Nereis diversicolor. Marine Ecology Progress Series, 56: 243-254.

EVANS, S. 1983. Production, predation and niche segregation in a marine shallow soft-bottom community. Marine Ecology Progress Series, 10: 147157.

FERNANDEZ, W.S., DIAS, G.M., MAJER, A.P., DELBONI, G.G., DENADAI, M.R. \& TURRA, A. 2017. Resource partitioning between sympatric starfish from tropical unconsolidated substrate: implications for coexistence and top-down control on benthic prey. Estuarine, Coastal and Shelf Science, 196: 141-149.

GARRITY, S.D. 1984. Some adaptations of marine gastropods to physical stress on a tropical rocky shore. Ecology, 65: 559-574.

HELMUTH, B., BROITMAN, B.R., BLANCHETE, C.A., GILMAN, S., HALPIN, P., HARLEY, G.D.G., O'DONNELL, M.J., HOFMANN, G.E., MENGE, B. \& STRICKLAND, D. 2006. Mosaic patterns of thermal stress in the rocky intertidal zone: implications for climate change. Ecological Monographs, 76: 461-479.

HOTHORN, T., BRETZ, F. \& WESTFALL, P. 2008. Simultaneous inference in general parametric models. Biometrical fournal, 50: 346-363.

HYSLOP, E.J. 1980. Stomach content analysis - a review of methods and their application. Fournal of Fish Biology, 17: 41 1-429.

KELAHER, B.P., LEVINTON, J.S. \& HOCH, J.M. 2003. Foraging by the mud snail, Ilyanassa obsoleta, modulates spatial variation in marine benthic communities. Fournal of Experimental Marine Biology and Ecology, 292: 139-157.

LAKE, P.S. 1990. Disturbing hard and soft-bottom communities: a comparison of marine and freshwater environments. Australian fournal of Ecology, 15: $477-488$

LASTRA, M., PAGE, H.M., DUGAN, J.E., HUBBARD, D.M. \& RODIL, I.F. 2008. Processing of allochthonous macrophyte subsides by sandy beach consumers: estimates of feeding rates and impact on food resources. Marine Biology, 154: 163-174.

LINK, J.S. 2002. Do food web theory work for marine ecosystems? Marine Ecology Progress Series, 230: 1-9.

LÓPEZ, G.R. \& CHENG, I.J. 1983. Synoptic measurements of ingestion rate, ingestion selectivity and absorption efficiency of natural foods in the deposit-feeding molluscs Nucula annulata (Bivalvia) and Hydrobia totteni (Gastropoda). Marine Ecology Progress Series, 11: 55-62.

MaLACHLAN, A., de RUYCK, A. \& HACKING, N. 1996. Community structure on sandy beaches: patterns of richness and zonation in relation to tide range and latitude. Revista Chilena de Historia Natural, 69: 451-467.

MaLACHLAN, A. \& TURNER, I. 1994. The interstitial environment of sandy beaches. Marine Ecology, 15: 177-211.

MALAQUIAS, M.A.E., CONDINHO, S., CERVERA, J.L. \& SPRUNG, M. 2004. Diet and feeding biology of Harminoea orbygiana (Mollusca: Gastropoda: Cephasaspidea). Fournal of the Marine Biological Association of the United Kingdom, 84: 767-772.

MARCUS, E. \& MARCUS, E. 1959. Studies on Olividae. Boletim Faculdade de Filosofia e Ciências da Universidade de São Paulo, Zoologia, 22: 99-188.

MARSHALL, D.J. \& McQUAID, C.J. 2011. Warming reduces metabolic rate in marine snails: adaptation to fluctuating high temperatures challenges the metabolic theory of ecology. Proceeding of the Royal Society of London Series B, 278: 281-288.

MARTINEZ, M.L., MENDOZA-GONZÁLEZ, G., SILVA-CASARÍN, R. \& MENDOZA-BALDWIN, E. 2014. Land use changes and sea level rise may induce a "coastal squeeze" on the coasts of Veracruz, Mexico. Global Environmental Changes, 29: 180-188.

MORLEY, S.A., TOFT, J.D. \& HANSON, K.M. 2012. Ecological effects of shoreline armoring on intertidal habitats of a Puget sound urban estuary. Estuaries \& Coasts, 35: 774-784
MORSE, A.P. \& PETERS, W.S. 2016. Opportunistic suspension feeding in the intertidal gastropod Olivella columellaris and its implication for the regulation of tidal migration. Ciencias Marinas, 42: 289-294.

NAMIKAS, S.L., EDWARDS, B.L., BITTON, M.G.A., BOOTH, J.L. \& ZHU, Y. 2010. Temporal and spatial variabilities in the surface moisture content of a fine-grained beach. Geomorphology, 114: 303-310.

NEL, R., GAMPBELL, E.E., HARRIS, L., HAUSER, L., SGHOEMAN, D.S., McLACHLAN, A., DU PREEZ, D.R., BEZUIDENHOUT, K. \& SCHLACHER, T.A. 2014. The status of sandy beach science: past trends, progress, and possible futures. Estuarine, Coastal and Shelf Science, 150: $1-10$.

NEWELL, R.C., PYE, V.I. \& AHSANULLAH, M. 1971. Factors affecting the feeding rate of the winkle Littorina littorea. Marine Biology, 9: 138-144.

NORDSTROM, M.G., LINDBLAD, P., AARNIO, K. \& BONSDORFF, E. 2010. A neighbor is a neighbor? Consumer diversity, trophic function and spatial variability in benthic food webs. Fournal of Experimental Marine Biology and Ecology, 391: 101-111.

NUCGI, P.R., TURRA, A. \& MORGADO, E.H. 2001. Diversity and distribution of crustaceans from 13 sheltered beaches along São Sebastião Channel, southeastern Brazil. Fournal of the Marine Biological Association of the United Kingdom, 81: 475-484.

O'HARA, R.B. \& KOTZE, D.J. 2010. Do not log-transform count data. Methods in Ecology and Evolution, 1: 118-122.

OKSANEN, J., BLANCHET, F.G., FRIENDLY, M., KINDT, R., LEGENDRE, P., MaGLINN, D., MINCHIN, P.R., O'HARA, R.B., SIMPSON, G.L., SOLYMOS, P., STEVENS, M.H.M., SZOECS, E. \& WAGNER, H. 2018. Vegan: community ecology package. Available at: https: //CRAN.R-project.org/package=vegan/. Accessed 10 May 2019.

PALMER, M.A. 1984. Invertebrate drift: behavioral experiments with intertidal meiobenthos. Marine Behavior and Physiology, 10: 235-253.

PETRACGO, M., GAMARGO, R.M., TARDELLI, D.T. \& TURRA, A. 2014. Population biology of the gastropod Olivella minuta (Gastropoda, Olividae) on two sheltered beaches in southeastern Brazil. Estuarine, Coastal and Shelf Science, 150: 149-156.

PHILLIPS, D.W. 1977. Avoidance and escape responses of the gastropod mollusk Olivella biplicata to predatory asteroids. Fournal of Experimental Marine Biology and Ecology, 28: 77-86.

PILÓ, D., BARBOSA, A.B., TEODÓSIO, M.A., CRUZ, J. \& CHÍCHARO, L. 2018. Are submarine groundwater discharges affecting the structure and physiological status of rocky intertidal communities? Marine Environmental Research, 136: 158-173.

PINCEBOURDE, S., SANFORD, E. \& HELMUTH, B. 2008. Body temperature during low tide alters the performance of a top intertidal predator. Limnology \& Oceanography, 53: 1562-1573.

PINCKNEY, J. \& ZINGMARK, R.G. 1991. Effects of tidal stage and sun angles on intertidal benthic microalgal productivity. Marine Ecology Progress Series, 76: 81-89.

PONTEE, N. 2013. Defining coastal squeeze: a discussion. Ocean $\&$ Coastal Management, 84: 204-207.

QUILLIEN, N., NORDSTROM, M., GAUTHIER, O., BONSDORFF, E., PAULES, Y.M. \& GRALL, J. 2015. Effects of macroalgal accumulations on the variability in zoobenthos of high-energy macrotidal sandy beaches. Marine Ecology Progress Series, 522, 97-114.

R CORE DEVELOPMENT TEAM. 2018. $R$ : a language and environment for statistical computing, version 3.50. R Foundation for Statistical Computing, Vienna. Available at: www.R-project.com. Accessed 10 May 2018.

RHOADS, D.C. \& YOUNG, D.K. 1970. The influence of deposit feeding organisms on sediment and community trophic structure. Fournal of Marine Research, 28: 143-161.

SCHLAGHER, T.A., SGHOEMAN, D.S., DUGAN, J., LASTRA, M., JONES, A., SCAPINI, F. \& MaLACHLAN, A. 2008. Sandy beach ecosystems: key features, sampling issues, management challenges and climate change impacts. Marine Ecology, 29: 70-90.

SERÔDIO, J., COELHO, H., VIEIRA, S. \& CRUZ, S. 2006. Microphytobenthos vertical migratory photoresponse as characterized by lightresponse curves of surface biomass. Estuarine, Coastal and Shelf Science, $\mathbf{6 8}$ : $547-556$. 
SKOV, M.W., HARTNOLL, R.G., RUWA, R.K., SHUNULA, J.P., VANNINI, M. \& CANNICGI, S. 2005. Marching to a different drummer: crabs synchronize reproduction to a 14-month lunar-tidal cycle. Ecology, 86: $1164-1171$.

THIEL, M. \& ULRICH, N. 2002. Hard rock versus soft bottom: the fauna associated with intertidal mussel beds on hard bottoms along the coast of Chile, and considerations on the functional role of mussel beds. Helgoland Marine Research, 56: 98.

VIEIRA, S., GOELHO, H., NOLASCO, R., SERÔDIO, J., BARNES, R. \& QUEIROGA, H. 2010. The circatidal rhythm of the estuarine gas- tropod Hydrobia ulvae (Gastropoda: Hydrobiidae). Biological Fournal of the Linnean Society, 100: 439-450.

WHITLACH, R.B. \& OBREBSKI, S. 1980. Feeding selectivity and coexistence in two-deposit feeding species. Marine Biology, 58: 219 225.

WILSON, K.A. 1989. Ecology of mangrove crabs: predation, physical factors and refuges. Bulletin of Marine Science, 44: 263-273.

ZUUR, A., IENO, E.N., WALKER, N., SAVELIEV, A.A. \& SMITH, G.M. 2009. Mixed effects model and extensions in ecology with $R$. Springer, New York. 